Marquette University

e-Publications@Marquette

College of Nursing Faculty Research and

Publications

Nursing, College of

$1-2015$

\title{
Tumor Growth Increases Neuroinflammation, Fatigue and Depressive-like Behavior Prior to Alterations in Muscle Function
}

\author{
Diana M. Norden \\ Ohio State University - Main Campus \\ Sabahattin Bicer \\ Ohio State University - Main Campus \\ Yvonne Clark \\ Ohio State University - Main Campus \\ Runfeng Jing \\ Ohio State University - Main Campus \\ Christopher J. Henry \\ Ohio State University - Main Campus
}

See next page for additional authors

Follow this and additional works at: https://epublications.marquette.edu/nursing_fac

Part of the Nursing Commons

\section{Recommended Citation}

Norden, Diana M.; Bicer, Sabahattin; Clark, Yvonne; Jing, Runfeng; Henry, Christopher J.; Wold, Loren E.; Reiser, Peter J.; Godbout, Jonathan P.; and McCarthy, Donna O., "Tumor Growth Increases Neuroinflammation, Fatigue and Depressive-like Behavior Prior to Alterations in Muscle Function" (2015). College of Nursing Faculty Research and Publications. 354.

https://epublications.marquette.edu/nursing_fac/354 


\section{Authors}

Diana M. Norden, Sabahattin Bicer, Yvonne Clark, Runfeng Jing, Christopher J. Henry, Loren E. Wold, Peter J. Reiser, Jonathan P. Godbout, and Donna O. McCarthy 
1 Tumor Growth Increases Neuroinflammation, Fatigue and Depressive-like Behavior Prior to Alterations in Muscle Function

4 Diana M. Norden $^{\mathrm{a}}$, Sabahattin Bicer ${ }^{\mathrm{b}}$, Yvonne Clark $^{\mathrm{c}}$, Runfeng Jing ${ }^{\mathrm{c}}$, Christopher J. Henry ${ }^{\mathrm{a}}$,

5 Loren E. Wold ${ }^{\mathrm{c}, \mathrm{d}}$, Peter J. Reiser ${ }^{\mathrm{b}}$, Jonathan P. Godbout ${ }^{\mathrm{a}, \mathrm{e}}$, and Donna O. McCarthy ${ }^{\mathrm{c}}$

$7{ }^{\text {a }}$ Department of Neuroscience, The Ohio State University, 333 W. $10^{\text {th }}$ Ave., Columbus, OH 843210.

$9{ }^{\mathrm{b}}$ Division of Biosciences, College of Dentistry, The Ohio State University, 305 W. $12^{\text {th }}$ Ave., 10 Columbus, $\mathrm{OH}$

$11{ }^{\mathrm{c} C}$ College of Nursing, The Ohio State University, 1585 Neil Ave., Columbus, OH

$12{ }^{\mathrm{d}}$ Department of Physiology and Cell Biology, 370 W. $9^{\text {th }}$ Ave., The Ohio State University,

13 Columbus, $\mathrm{OH}$

$14{ }^{\mathrm{e}}$ Institute for Behavioral Medicine Research, The Ohio State University, 460 Medical Center Dr.

15 Columbus, $\mathrm{OH}$

$16{ }^{\S}$ To whom correspondence should be addressed: Donna McCarthy, 235 Clark Hall, Marquette

17 University, P.O. Box 1881, Milwaukee WI, 53202-1881, Tel: 414-288-3820, Email:

18 donnalee.mccarthy@mu.edu

20 Key Words: fatigue, depression, neuroinflammation, cancer, minocycline, cytokines 


\section{Abstract}

2 Cancer patients frequently suffer from fatigue, a complex syndrome associated with loss

3 of muscle mass, weakness, and depressed mood. Cancer-related fatigue (CRF) can be present at

4 the time of diagnosis, during treatment, and persists for years after treatment. CRF negatively

5 influences quality of life, limits functional independence, and is associated with decreased

6 survival in patients with incurable disease. Currently there are no effective treatments to reduce

7 CRF. The aim of this study was to use a mouse model of tumor growth and discriminate between

8 two main components of fatigue: loss of muscle mass/function and altered mood/motivation.

9 Here we show that tumor growth increased fatigue- and depressive-like behaviors, and reduced

10 body and muscle mass. Decreased voluntary wheel running activity (VWRA) and increased

11 depressive-like behavior in the forced swim and sucrose preference tests were evident in tumor-

12 bearing mice within the first two weeks of tumor growth and preceded the loss of body and

13 muscle mass. At three weeks, tumor-bearing mice had reduced grip strength but this was not

14 associated with altered expression of myosin isoforms or impaired contractile properties of

15 muscles. These increases in fatigue and depressive-like behaviors were paralleled by increased

16 expression of IL-1 $\beta$ mRNA in the cortex and hippocampus. Minocycline administration reduced

17 tumor-induced expression of IL-1 $\beta$ in the brain, reduced depressive-like behavior, and improved

18 grip strength without altering muscle mass. Taken together, these results indicate that

19 neuroinflammation and depressed mood, rather than muscle wasting, contribute to decreased

20 voluntary activity and precede major changes in muscle contractile properties with tumor

21 growth. 


\section{Introduction}

Fatigue is the most common symptom reported by cancer patients before and during treatment, and can continue for years after completion of treatment (Bower and Lamkin, 2013; Husson et al., 2013; Minton et al., 2012). It often co-occurs with depression, (Bower et al., 2011; Kim et al., 2012; Pertl et al., 2013) and reduces quality of life (Vissers et al., 2013). However, the cause of cancer-related fatigue (CRF) is unknown (Berger et al., 2012) and there are no effective treatments (Bower and Lamkin, 2013).

Mounting evidence indicates that CRF and depressed mood are associated with elevated serum levels of pro-inflammatory mediators, including C-reactive protein (Pertl et al., 2013) and cytokines such as tumor necrosis factor-alpha (TNF $\alpha$ ), interleukin (IL)-1 $\beta$ and IL-6 (Saligan and Kim, 2012; Wood and Weymann, 2013). These cytokines are likely produced by the tumor and host tissues in response to tumor growth or anti-tumor treatments (Wang et al., 2012). Proinflammatory cytokines increase expression of biomarkers of autophagy and the ubiquitinproteasome pathway in skeletal muscle which reduce muscle mass (Fearon et al., 2012; Sandri, 2013; Toledo et al., 2011). The loss of muscle mass, or sarcopenia, can be seen even before cancer treatment (Baracos et al., 2010; Cao et al., 2010) and likely explains patient complaints of exhaustion associated with physical activity and muscle weakness (Hofman et al., 2007).

Systemic increases in pro-inflammatory mediators mount a complex response that is not limited to the periphery. The central nervous system (CNS) interprets inflammatory responses that originate in the periphery. Microglia, innate immune cells of the CNS, contribute to the propagation of inflammatory cytokines and secondary messengers throughout the CNS (Wood and Weymann, 2013). Increases in brain IL-1 $\beta$ are linked to both muscle atrophy (Braun et al., 2011) and depressed mood (Haroon et al., 2012). Recent evidence from rodent models indicates 
1 that inflammatory cytokines within the CNS are associated with symptoms of fatigue, such as

2 decreased voluntary wheel running activity (Carmichael et al., 2006). Although a link between

3 inflammation and fatigue in cancer patients has been suggested (Bower, 2007), no clear

4 connection between CNS inflammation and CRF has been reported.

The aim of this study was to discriminate between loss of muscle mass and depressed

6 mood in a mouse model of CRF. Fatigue was modeled as reduced voluntary wheel running

7 activity (VWRA) (Novak et al., 2012; Wood et al., 2006; Zombeck et al., 2013) and weakness

8 was modeled as reduced forelimb grip strength (Murphy et al., 2012). Depressed mood was

9 modeled using the sucrose preference (Lamkin et al., 2011) and forced swim tests (Pyter et al.,

10 2009). We show that depressive-like behavior and brain cytokine expression were increased and

11 VWRA was decreased in tumor-bearing mice prior to the loss of muscle mass and decrease in

12 grip strength. Decreased grip strength, however, was not associated with reduced contractile

13 properties of skeletal muscle. Administration of minocycline to tumor-bearing mice reduced

14 inflammatory cytokine expression in the brain, reduced depressive-like behavior, and increased

15 grip strength with no effects on muscle mass. These data indicate that grip strength may reflect

16 motivation or mood as much as muscle strength. Overall, decreased physical activity and

17 depressive-like behaviors are mediated by pro-inflammatory cytokine expression in the brain of

18 tumor-bearing mice.

20 2. Materials and methods

212.1 Mice

22 Adult female BALB/c x DBA/2 F1 (CD2F1) adult (10 weeks) mice weighing 20-22 g were

23 obtained from Charles River Laboratories. Female mice were used because we and others have 
1 shown that tumor-bearing females maintain their food intake and lose a smaller percent of body

2 mass than male mice (Cosper and Leinwand, 2011) and male mice often gnaw and bite at the

3 tumor site (Yang et al., 2014). Mice were housed 1-3 per cage and maintained at $25^{\circ} \mathrm{C}$ under a 12

4 h light cycle with ad libitum access to water and rodent chow. All procedures were performed in

5 accordance with the National Institute of Health Guidelines for the Care and Use of Laboratory

6 Animals and were approved by The Ohio State University Institutional Animal Care and Use 7 Committee.

$9 \quad 2.2$ Mouse model of tumor-growth

10 The colon26 adenocarcinoma (colon26) cell line was maintained in culture and prepared for

11 injection as previously described (Xu et al., 2011). Mice were injected subcutaneously between

12 the scapulae with $5 \times 10^{5}$ cells in $0.2 \mathrm{ml}$ of PBS or PBS alone. This tumor cell line secretes IL-6

13 and TNF- $\alpha$ (Graves et al., 2006) and does not metastasize when injected subcutaneously

14 (Okayama et al., 2009). Tumor growth is usually palpable by day 7 and mice become moribund

15 by day 24 of tumor-growth. In the present study, all data collection was completed by day 21 of

16 tumor growth. Body mass and food and water intake were monitored three times a week for the

17 first 2 weeks, and daily during the $3^{\text {rd }}$ week. Behavioral data were collected in the range of 1

18 week (7 day), 2 weeks (12-14 day) and 3 weeks (19-21 day) following tumor cell inoculation.

19 Except as noted below, mice were euthanized by inhalation of $\mathrm{CO}_{2}$ gas and blood was withdrawn

20 by cardiac puncture. Hindlimb muscles were dissected, weighed, and snap frozen in liquid

21 nitrogen until biochemical analyses; tumor mass was removed and weighed; the brain was

22 quickly dissected and hippocampus and cortex brain tissue were snap frozen in liquid nitrogen. 


\subsection{Oral minocycline administration}

2 Mice were housed 3 per cage for the minocycline study. Mice were provided bottles of water or

3 water supplemented with $1 \mathrm{mg} / \mathrm{ml}$ minocycline for a dose of $100 \mathrm{mg} / \mathrm{kg} / \mathrm{day}$ (Sigma, St. Louis)

4 starting one day after PBS or tumor cell injection. Water bottles were changed every other day

5 throughout the study. There were no differences in total fluid intake between any of the

6 experimental groups (Control-minocyline, Control-vehicle, Tumor-minocycline, and Tumor-

7 Vehicle) (data not shown).

92.4 Grip strength measurements

10 Forelimb grip strength was determined as previously described (Murphy et al., 2012). In brief,

11 each mouse was allowed to grasp a platform with both forelimbs and was pulled by the tail until

12 it released itself from the platform (Columbus Instruments, model 1027DSM). Peak force

13 measurements $(\mathrm{N})$ were recorded in five trials and the average was calculated. Because smaller

14 mice have smaller grip strength, peak force was also normalized to body mass of the animal.

162.5 Voluntary wheel running activity

17 Fatigue-like behavior was determined using voluntary wheel running activity as previously

18 described (Zombeck et al. 2013). Mice were singly housed for studies in which voluntary wheel

19 running activity (VWRA) was determined. Mice were acclimated to a four inch running wheel in

20 the cage for one week, and baseline measures (week 0) of VWRA were recorded overnight prior

21 to injection with tumor cells or PBS. Wheels were again placed in the home cages of all mice

22 overnight on days 7 (week 1), 14 (week 2) and 19 (week 3) of tumor growth and the total number

23 of turns was digitally recorded (Columbus Instruments, model 0297-004M). 


\section{$2 \quad 2.6$ Home cage locomotor activity}

3 Mice were maintained in their home cage with a floor area of 26 x $20 \mathrm{~cm}$, and activity was video

4 recorded for 3 minutes. On the video records, cages were divided into 6 identical virtual 5 rectangles and the number of line crossings was determined.

$7 \quad 2.7$ Depressive-like behavior

8 Depressive-like behavior was determined using resignation in the forced swim test (FST) and

9 anhedonia in the sucrose preference test, as described previously (Godbout et al., 2008; Henry et

10 al., 2008). In the FST, mice were placed in an inescapable cylinder (diameter $16 \mathrm{~cm}$, height

$1130 \mathrm{~cm}$ ) containing $15 \mathrm{~cm}$ of water and behavior was recorded for five min. The latency to

12 become immobile and the duration of immobility were determined. For the sucrose preference

13 test, mice were provided two solutions: water or water supplemented with $2 \%$ sucrose. Mice

14 were fluid- and food-deprived for $2 \mathrm{~h}$ prior to testing. At the start of the dark phase of the

15 photoperiod, plain water and the sucrose water were both placed in each home cage overnight

16 (15 h). At the end of each testing period, the fluid content was measured and the percent of

17 sucrose preference was determined.

192.8 In vitro Muscle Contractile Properties and Fatigue Resistance

20 Contractile properties of freshly isolated hindlimb muscles were determined, as described in

21 detail previously (Bicer et al., 2009). In brief, mice were euthanized with $\mathrm{CO}_{2}$ inhalation and one

22 soleus muscle and one EDL muscle were removed and placed in oxygenated Ringer's solution.

23 One muscle was maintained in oxygenated Ringer's solution in a petri dish at room temperature 
1 while contractile measurements were made on the other muscle. The order in which the soleus

2 and EDL were studied was alternated between experiments and it was previously determined that

3 this did not impact the results (Bicer et al., 2009). All of the measurements were made at room

4 temperature $\left(21 \cdot 2-23 \cdot 8^{\circ} \mathrm{C}\right)$. The muscle was mounted horizontally in an in vitro apparatus (model

5 801C, Aurora Scientific, Aurora, Ontario, Canada) and was continuously superfused with

6 oxygenated Ringer's solution ( $137 \mathrm{mM} \mathrm{NaCl}, 5 \mathrm{mM} \mathrm{KCl}, 13 \mathrm{mM} \mathrm{NaHCO}{ }_{3}, 1.8 \mathrm{mM} \mathrm{KH}_{2} \mathrm{PO}_{4}, 2$

$7 \mathrm{mM} \mathrm{CaCl}_{2}, 11 \mathrm{mM}$ glucose, $1 \mathrm{mM} \mathrm{MgSO}_{4}$, and $0.025 \mathrm{mM}$ tubocurarine chloride). One tendon of

8 the muscle was glued to a wire hook and the other tendon was similarly attached to a force

9 transducer (model 300B, Aurora Scientific). Care was taken to ensure that none of the glue

10 contacted the muscle fibers. The hook and transducer were mounted on three-way positioners.

11 The muscle was set at optimal length by adjusting the position of the hook or transducer, until

12 maximal twitch force was generated. The muscle was then stimulated to elicit five twitches and

13 the peak twitch force, time to peak force, and time from peak force to one-half relaxation during

14 each twitch were recorded. Next, the tetanic force-frequency curve was established using

15 stimulus trains. The lowest stimulation frequency that yielded the maximal peak tetanic force in

16 the force-frequency measurements was used to measure peak tetanic force and the time from the

17 last stimulus to one-half relaxation. Five tetani, spaced 2 minutes apart, were studied in each

18 muscle and the means were calculated. Maximal twitch and tetanic forces were also normalized

19 to muscle cross-sectional area which was estimated from muscle mass and length measurements

20 (Bicer et al., 2009). After a five minute rest, fatigue resistance was measured by stimulating the

21 muscle with trains at $1 \mathrm{~Hz}$ consisting of pulses (pulse duration $0.1 \mathrm{~ms}$ ) at $70 \mathrm{~Hz}$ for $400 \mathrm{~ms}$. A

22 fatigue index was quantitated as the peak force during the train at 2 minutes divided by the peak

23 force during the initial train. 


\subsection{In situ contractile properties}

3 Control and tumor-bearing mice were anesthetized with urethane and placed in a supine position

4 on an in situ apparatus (model 809B, Aurora Scientific). The sciatic nerve was exposed above

5 the knee joint and the uninsulated end of a stainless steel wire electrode (Biomed Wire AS 631,

6 Cooner Wire Co.) was placed in contact with the nerve. The other end of the wire was connected

7 to a stimulator (model 701C, Aurora Scientific) which was gated with another stimulator (Grass

8 Technologies, model S48). The knee was clamped and the skin overlying the tibialis anterior was

9 cut. The distal tendon of the muscle was glued to a wire which was hooked to the arm of a force

10 transducer (model S100-5N, Strain Measurement Devices, Wallingford CT) that was connected

11 to a custom-built power supply/amplifier. The muscle was set to the length at which the greatest

12 peak twitch force was generated. The stimulation and recording protocols were identical to the

13 protocol used to determine in vitro contractile properties. Muscle cross-sectional area was

14 determined as in the in vitro muscle measurements. Core temperature of the mouse was

15 maintained with a heating pad.

16

\section{$17 \quad 2.10$ Gel electrophoresis}

18 The preparation of samples and of gels for the analysis of myosin heavy chain (MHC) and light

19 chain (MLC) isoform composition was identical to that described previously (Bicer et al., 2009).

20 Briefly, MHC isoforms were run on $8 \%$ acrylamide gels with $30 \%$ glycerol. MLC isoforms were

21 analyzed on $12 \%$ acrylamide (no glycerol). The gels were silver-stained and the relative amounts

22 of fast- and slow-type MHC isoforms in each sample were determined relative to total MHC in

23 the same sample. 


\subsection{RNA isolation and RT-PCR analysis}

3 RNA was isolated from hippocampus and cortex brain sections using the Tri-Reagent protocol

4 (Sigma) and reverse transcribed to cDNA using the High Capacity cDNA Reverse Transcription

5 kit (Applied Biosystems). Quantitative PCR was performed using the Applied Biosystems

6 Assay-on-Demand Gene Expression protocol. In brief, experimental cDNA was amplified with

7 an ABI PRISM 7300-sequence detection system (Applied Biosystems) by real-time PCR and

8 normalized based on reference cDNA (GAPDH). Data were analyzed with the comparative

9 threshold cycle method.

\subsection{Immunohistochemistry and digital image analyses}

12 Mice were deeply anesthetized by $\mathrm{CO}_{2}$ inhalation and transcardially perfused with sterile PBS

13 followed by $4 \%$ formaldehyde. Brains were post-fixed in $4 \%$ formaldehyde for $24 \mathrm{~h}$ and

14 cryoprotected in $20 \%$ sucrose for $48 \mathrm{~h}$. Preserved brains were frozen using dry-ice cooled

15 isopentane and sectioned $(25 \mu \mathrm{m})$ using a Microm HM550 cryostat. Iba-1 staining was

16 performed as previously described (Wohleb et al., 2011). In brief, free-floating sections were

17 blocked and then incubated with rabbit anti-mouse Iba-1 antibody (Wako Chemicals) overnight

18 at $4^{\circ} \mathrm{C}$. Sections were washed with PBS and incubated with a fluorochrome-conjugated

19 secondary antibody (Alexa Flour 594). Fluorescent images were visualized using an

20 epifluorescent Leica DM5000B microscope and were captured using a Leica DFC300 FX

21 camera and imaging software. Quantitation was assessed using digital image analysis (Donnelly

22 et al., 2009) in the hippocampus (12 representative images) and prefrontal cortex (6 
1 representative images) at 20x magnification. Threshold staining was determined using NIH

2 ImageJ software. Results are reported as the average percent area for Iba- $1^{+}$staining.

$4 \quad 2.13$ IL-6 ELISA

5 IL-6 was determined from plasma using the BD OptEIA Mouse IL-6 ELISA, according to the

6 manufacturer's instructions (BD Biosciences). Absorbance was read at $450 \mathrm{~nm}$ using a Synergy

7 HT Plate Reader (Bio-tek instruments). The assay was sensitive to $10 \mathrm{ng} / \mathrm{ml} \mathrm{IL-6}$ and intra-assay 8 coefficients of variation were less than $10 \%$.

2.14 Statistical Analysis

11 Data were subjected to a Shapiro-Wilk test using Statistical Analysis Systems (SAS) software

12 (Cary, NC). Observations greater than three interquartile ranges from the first and third quartile

13 were considered outliers and were excluded in the subsequent analyses. To determine significant

14 main effects and interactions between main factors, data were analyzed using one-, two-, or

15 three-way ANOVA using the General Linear Model procedures of SAS. Differences between

16 group means were evaluated with the $t$-test using the Least-Significant Difference procedure of

17 SAS. All data are expressed as treatment means \pm standard error of the mean (SEM).

19 3. Results

203.1 Tumor growth was associated with muscle loss and muscle weakness

21 To begin to understand the effects of tumor growth on muscle function and mood, mice were

22 inoculated subcutaneously between the scapulae with C26 adenocarcinoma cells. Tumor mass

23 was $0.3 \mathrm{~g}$ by 2 weeks and reached an average of $1.3 \mathrm{~g}$ (5\% of body mass) by 3 weeks 
$1 \quad\left(\mathrm{~F}_{1,24}=38.22, p<0.0001\right.$, Fig.1A). Body mass of tumor-bearing mice was not different from

2 healthy controls at 1 and 2 weeks, but was reduced by 3 weeks $\left(F_{2,30}=3.51, p<0.05\right.$, Fig.1B).

3 There was no decline in muscle mass within 2 weeks of tumor growth; however, there was a

4 significant loss of gastrocnemius muscle mass by three weeks of tumor growth $\left(F_{1,26}=13.17\right.$,

$5 p<0.02$, Fig.1C). Tumor growth also reduced the mass of tibialis cranialis, soleus, and biceps

6 brachii muscles $(p<0.05$ for each, data not shown).

7 Next, the extent to which loss of muscle mass contributed to muscle weakness was

8 determined. In this experiment, forelimb grip strength was determined prior to tumor cell

9 inoculation (week 0) and at weeks 2 and 3 of tumor growth. Tumor growth decreased grip

10 strength $\left(\mathrm{F}_{1,66}=4.72, p<0.03\right)$ in a time-dependent manner $\left(\mathrm{F}_{1,66}=3.08, p<0.05\right)$ (Fig.1D). Grip

11 strength of tumor-bearing mice was similar to controls at baseline and 2 weeks after tumor cell

12 inoculation but was decreased compared to controls by 3 weeks ( $p<0.003$, Fig.1D). Similar data

13 were obtained when grip strength was normalized to body mass $\left(\mathrm{F}_{1,16}=8.84, p<0.02\right.$, Fig.1E).

3.2 Effects of tumor growth on contractile properties of skeletal muscle

16 To better understand the decline in grip strength in tumor-bearing mice, we examined

17 contractile properties of the soleus and EDL from tumor-bearing mice in vitro at 1, 2, and 3

18 weeks after tumor cell inoculation and from control mice at 4 weeks after saline injection.

19 Absolute twitch force (i.e., not normalized with muscle cross-sectional area) in the soleus was

20 not affected by tumor burden (Table 1). In contrast, absolute tetanic force in the soleus was

21 significantly reduced after two and three weeks of tumor burden $\left(\mathrm{F}_{1,24}=5.468, p<0.007\right)$.

22 Absolute twitch force in the EDL was significantly lower at one, two and three weeks of tumor

23 burden $\left(\mathrm{F}_{1,24}=4.852, p<0.011\right)$, as was absolute tetanic force at one and three weeks $\left(\mathrm{F}_{1,24}=3.185\right.$, 
$1 p<0.04$, Table 2). Peak twitch and tetanic forces normalized to cross sectional area of the muscle

2 (specific force) were not different from control animals at weeks 1, 2 or 3 of tumor growth in

3 either the soleus (Table 1) or EDL (Table 2). In the soleus, the time to peak twitch force and the

4 time to one-half relaxation were significantly longer in tumor-bearing mice, beginning at one

5 week after inoculation $(p<0.05)$. The time to one-half relaxation of the tetanus was, however,

6 unaltered by tumor growth. In the EDL, relaxation during the tetanus was not affected by tumor

7 growth. Moreover, fatigue resistance was not altered in either muscle at weeks 1, 2, or 3 of tumor 8 growth.

9 Given the absence of significant effects of tumor growth on normalized muscle force 10 generation in vitro, in situ contractile analyses were performed on the tibialis anterior muscle at

11 three weeks of tumor growth. Absolute peak twitch and tetanic forces were lower in the tumor-

12 bearing mice, compared to the control group $\left(F_{1,12}=8.863, p<0.01\right.$, Table3). However, the forces

13 normalized to cross sectional area, kinetics of contraction and relaxation, and fatigue resistance

14 were not different between control mice and tumor-bearing mice (Table 3).

15 Myosin heavy chain (MHC) and myosin light chain (MLC) are major determinants of

16 contractile properties in skeletal muscle. Therefore, we evaluated the MHC and MLC isoform

17 composition of the soleus and EDL in control and tumor-bearing mice on SDS gels. There were

18 no differences detected in MHC or MLC isoform expression in either the soleus or EDL between

19 control and tumor-bearing mice at three weeks of tumor growth (Fig.1S). Overall, these data

20 indicate that while tumor growth decreased skeletal muscle mass and reduced absolute grip

21 strength over time, myosin composition and normalized contractile forces of skeletal muscles

22 were not altered by tumor growth. 


\subsection{Tumor growth increased fatigue- and depressive-like behavior}

The lack of effect of tumor growth on normalized contractile force of muscle suggests

that tumor-associated changes in mood might decrease motivation of the tumor-bearing mice to engage in the grip strength test. To test this hypothesis, mice were evaluated for fatigue and depressive-like behaviors. In the first experiment, activity was assessed in control and tumorbearing mice using VWRA before tumor cell inoculation and again 1, 2, and 3 weeks later.

VWRA progressively declined in the tumor-bearing mice $\left(\mathrm{F}_{1,16}=15.23, p<0.001\right)$ (Fig.2A). VWRA was decreased by week $2(p<0.001)$ of tumor growth, prior to loss of muscle mass, and was further decreased by week $3(p<0.001)$ compared to controls.

To better understand the influence of tumor growth on mood, anhedonia (sucrose preference) was determined in control and tumor-bearing mice before tumor cell inoculation and again 1, 2 and 3 weeks of tumor growth. At baseline, all mice preferred drinking sucrose, i.e. over $80 \%$ of total fluid consumed (data not shown). Moreover, control mice maintained a preference for sucrose at each time point (Fig.2B). In tumor-bearing mice, however, sucrose preference was decreased $\left(\mathrm{F}_{1,100}=4.09, p<0.004\right)$ to $56 \%$ by 1 week $(p<0.006)$ and $52 \%$ by 2 weeks $(p<0.05)$ of tumor growth $($ Fig.2B). This decrease in sucrose preference was no longer present by week three of tumor growth.

To further examine the effects of tumor growth on mood in tumor-bearing mice, depressive-like behavior (resignation) was determined at 2 weeks using the forced swim test (FST). This time point represents a time when sucrose preference and VWRA were decreased in tumor-bearing mice, but body mass and muscle mass were not different from controls. Because these evaluations of mood/motivation can be confounded by differences in locomotion, home cage locomotor activity was determined prior to the FST. There was no difference in home cage 
1 activity between control and tumor-bearing mice at 2 weeks of tumor growth (Fig.2C).

2 Nonetheless, tumor-bearing mice were immobile faster $\left(\mathrm{F}_{1,12}=7.05, p<0.02\right.$, Fig.2D) and spent

3 more time immobile in the FST compared to controls $\left(\mathrm{F}_{1,12}=43.18, p<0.001\right.$, Fig.2E). Overall,

4 these data indicate that tumor growth was associated with increased depressive-like behavior at

5 the same time as VWRA was reduced in tumor-bearing mice.

3.4 Increased IL-1 $\beta$ and IL-6 mRNA expression in the brain of tumor-bearing mice

Our data indicate that tumor growth increased depressive-like behavior and decreased

9 VWRA prior to reducing grip strength and muscle mass in the tumor-bearing mice. Because

10 depressed mood is associated with increased levels of inflammatory cytokines within the brain,

11 IL-1 $\beta$, IL-6, and TNF $\alpha$ mRNA expression was determined at 2 and 3 weeks in the cortex (CX)

12 and hippocampus (HPC) of control and tumor-bearing mice. Tumor growth increased IL-1 $\beta$

13 mRNA expression in the HPC $\left(\mathrm{F}_{1,44}=24.17, p<0.0001\right)$ (Fig.3A). For example, IL-1 $\beta$ mRNA was

14 increased by 2 weeks after tumor cell inoculation $(p<0.03)$ and was further increased by 3 weeks

15 ( $p<0.004)$. A similar pattern for IL-1 $\beta$ mRNA expression was evident in the CX of tumor-

16 bearing mice $\left(\mathrm{F}_{1,37}=10.31, p<0.003\right.$, Fig. $\left.3 \mathrm{~B}\right)$. Tumor growth also tended to increase IL-6 mRNA

17 in the HPC $\left(\mathrm{F}_{1,44}=3.3, p=0.08\right)$ (Fig.3C) and $\mathrm{CX}\left(\mathrm{F}_{1,34}=4.15, p<0.05\right)$ (Fig.3D) by 3 weeks, but

18 not by 2 weeks. TNF $\alpha$ mRNA expression was not increased in tumor-bearing mice at either time

19 point (data not shown).

20 Next, microglial activated morphology was determined in the HPC and CX of control and

21 tumor-bearing mice at 3 weeks. Representative images of Iba-1 positive microglia from the HPC

22 and CX are shown in Fig.3E. There was no difference in Iba-1 immunoreactivity in the HPC

23 between control mice and tumor mice (top panels). In the CX, however, tumor-bearing mice had 
1 increased Iba-1 immunoreactivity. Microglia from the brain of tumor mice had larger cell bodies

2 with thicker and more condensed processes (Fig.3E). Proportional analysis of Iba-1 staining

3 (Wohleb et al., 2011) confirmed that tumors increased Iba-1 immunoreactivity in the CX

$4 \quad\left(\mathrm{~F}_{1,12}=4.65, p=0.05\right.$, Fig.3F). Taken together, these data indicate tumor growth was associated

5 with increased pro-inflammatory cytokine expression in the hippocampus and cortex and 6 increased Iba-1 immunoreactivity.

3.5 Minocycline attenuated depressive-like behavior, neuroinflammation, and restored grip

9 strength in tumor-bearing mice

10 Reduced VWRA, increased depressive-like behavior, and increased brain expression of IL-1 $\beta$

11 were evident by two weeks of tumor growth and preceded the reduction in muscle mass and grip

12 strength at three weeks. Therefore, minocycline, an anti-inflammatory agent and purported

13 microglial inhibitor (Nikodemova et al., 2006), was used to determine the extent to which

14 elevated IL-1 $\beta$ and IL-6 expression in the CNS contributes to altered behavior in tumor-bearing

15 mice. For this experiment, mice were administered minocycline in their drinking water from day

161 after tumor cell inoculation to the completion of the study.

17 Depressive-like behavior was determined at 2 weeks of tumor growth using the FST.

18 Consistent with our earlier finding (Fig. 2E), tumor-bearing mice had an increased total time

19 immobile in the FST $\left(\mathrm{F}_{1,46}=53.83, p<0.001\right)$ (Fig.4A). Tumor-bearing mice treated with

20 minocycline, however, had decreased total time immobile compared to tumor-bearing mice

21 given water $(\mathrm{F}(1,46)=7.65, p<0.01)(\mathrm{Fig} .4 \mathrm{~A})$. At 3 weeks of tumor growth, absolute (data not

22 shown $)$ and normalized grip strength were decreased in tumor-bearing mice $\left(\mathrm{F}_{1,22}=5.88, p<0.03\right)$

23 (Fig.4B). Administration of minocycline restored the normalized grip strength to the same levels 
1 as control mice $\left(\mathrm{F}_{1,22}=3.75, p=0.07\right)$ (Fig. $\left.4 \mathrm{~B}\right)$. After the completion of this test, mice were

2 euthanized and tumor mass, gastrocnemius muscle mass, plasma IL-6 levels and brain IL-1 $\beta$ and

3 IL-6 mRNA expression were determined. As expected, minocycline intervention had no

4 significant effect on tumor mass (Fig.4C) or gastrocnemius muscle mass (Fig.4D). Plasma IL-6

5 was increased in tumor-bearing mice $\left(\mathrm{F}_{1,23}=37.04, p<0.001\right)$ but was not changed by minocycline

6 administration (Fig.4E). Consistent with previous results (Fig.3), expression of IL-1 $\beta$ and IL-6

7 mRNA were increased in the cortex and hippocampus of tumor-bearing mice at 3 weeks of

8 tumor growth (Fig.5A-D). Minocycline intervention, however, blocked tumor associated

9 increases in IL-1 $\beta$ and IL-6 mRNA in the hippocampus and cortex $\left(\mathrm{F}_{1,46}=5.18, p<0.03\right.$, for each).

10 In conclusion, minocycline intervention had no effect on tumor size or muscle mass, but

11 ameliorated the tumor-associated effects on neuroinflammation, depressive-like behavior, and

12 grip strength normalized to body mass.

\section{4. Discussion}

15 Fatigue is a common and distressing symptom reported by cancer patients before, during,

16 and after cancer treatments. Patients with CRF often describe muscle weakness and reduced

17 effort tolerance which have a negative effect on quality of life and functional status (Hofman et

18 al., 2007). Muscle wasting and depressive symptoms are prevalent in patients with CRF and are

19 associated with higher mortality rates in cancer patients with persistent or incurable disease

20 (Mols et al., 2013). Therefore, treatments to reduce fatigue and depression in cancer patients are

21 needed to increase quality of life and perhaps prolong survival. In this study, a mouse model of

22 CRF was used to discriminate between loss of muscle mass and altered mood in the onset of

23 fatigue behaviors. Here we report that tumor-bearing mice demonstrate behaviors of fatigue 
1 (decreased VWRA) and depressed mood (resignation and anhedonia) prior to the onset of muscle

2 fatigue, as determined from in vitro measurements. In addition, the decreases in VWRA and grip

3 strength in tumor-bearing mice were not associated with decreases in contractile properties of

4 skeletal muscle. Depressive-like behavior in tumor-bearing mice was associated with increased

5 expression of IL-1 $\beta$ and IL-6 in the cortex and hippocampus, brain regions associated with mood

6 and motor activity. Treatment of the tumor-bearing mice with minocycline, an anti-inflammatory

7 agent and purported microglial inhibitor, did not affect tumor growth or muscle mass. However,

8 minocyline reduced tumor-induced depressive-like behavior and brain cytokine expression and

9 improved grip strength in tumor-bearing mice. Overall, these data support the hypothesis that

10 tumor induced cytokine-dependent changes in mood play a larger role in behaviors of CRF

11 compared to loss of skeletal muscle mass.

12 Consistent with other studies, tumor growth was associated with decreased body mass

13 and muscle mass (Acharyya et al., 2004; Xu et al., 2011). Moreover, reduced muscle mass was

14 associated with reduced grip strength by three weeks of tumor growth. Although absolute force

15 generating ability was reduced and was proportional to differences or decreases in muscle cross-

16 sectional area, fundamental contractile properties of the EDL and soleus in vitro, or the tibialis

17 anterior in situ were not altered by tumor burden (Tables 1-3) (Murphy et al., 2013). The lack of

18 differences in the in situ contractile properties of muscles of control and tumor-bearing mice,

19 other than absolute force generation, indicates that the neuromotor innervation was not

20 significantly impaired by tumor progression. These data are consistent with a clinical study

21 showing that absolute strength of the quadriceps muscle in cancer patients was decreased, but

22 was identical to control subjects when normalized to muscle cross sectional area (Weber et al.,

23 2009). Others have reported a decrease in muscle force generation, normalized with cross- 
1 sectional area, in association with cancer cachexia (Roberts et al., 2013; Toth et al., 2013).

2 Roberts et al. (2013) used a more severe tumor load (same number of tumor cells per injection,

3 but injected bilaterally in the flank region) and reported a decrease in specific force that was not

4 observed in the present study. The difference between the previous and current studies suggests

5 that the greater tumor load caused a decrease in specific force through a mechanism that was

6 independent of the loss of muscle mass. Murphy and co-workers (2012 and 2013) also report that

7 specific force generation is not affected by tumor burden, using the same model as in the present

8 study. Our results demonstrate that motor/behavioral deficits can precede a reduction in specific

9 force generation or muscle fatigue.

Several previous reports indicate that the myosin heavy chain isoform composition of

11 skeletal muscle, a major determinant of muscle contractile properties, changes with tumor burden

12 (Diffee et al., 2002; Taskin et al., 2014), whereas others reported no change in myosin heavy

13 isoform composition or myosin-based fiber type composition (Johns et al., 2014; Schmitt et al.,

14 2007). Consistent with no change in specific force generation, significant alterations in physical

15 activity were observed in tumor-bearing mice, compared to control mice, without any detectable

16 change in myosin isoform expression.

17 Reduced VWRA is a widely used model of fatigue in response to immune challenge

18 (Hopwood et al., 2009) or chemotherapy (Zombeck et al., 2013). A key finding in this study was

19 that reduced VWRA and depressive-like behavior occurred in tumor-bearing mice prior to

20 significant weight or muscle loss. The decrease in VWRA was not associated with reduced home

21 cage activity. These findings indicate that tumor growth did not cause general malaise. Instead,

22 tumor-bearing mice likely had reduced motivation to run, suggesting that depressed mood plays

23 a role in CRF (Novak et al., 2012). In support of this idea, tumor-bearing mice showed reduced 
1 sucrose preference at one and two weeks after tumor cell inoculation, and increased time

2 immobile in the FST at the two week time point. Other studies have shown that peripheral

3 tumors induce depressive-like behavior concurrent with reduced body mass in rodents (Lamkin

4 et al., 2011; Pyter et al., 2009; Yang et al., 2014). Our study, however, shows that depressive-like

5 behavior occurs early in the course of tumor growth and precedes tumor induced weight loss or

6 muscle wasting. Of note, the tumor-bearing mice no longer had a reduced preference for sucrose

7 at the three week time point. This observation suggests that sucrose solution became the

8 preferred calorie source for mice with significant tumor burden, though we observed no decease

9 in solid food intake or increase in total fluid intake (data not shown).

10 CRF involves complex, interacting effects of tumor growth on multiple dimensions

11 involved in the functional status of the cancer patient. Therefore, the underlying mechanisms of

12 CRF are unknown but may be related to a heightened inflammatory state. In rodent models of

13 inflammation and immune activation, elevated IL-1 $\beta$ expression in the brain has been associated

14 with fatigue and depression (Carmichael et al., 2006; Godbout et al., 2008). In the current study,

15 we provide several lines of evidence that increased pro-inflammatory cytokine expression in the

16 brain influences fatigue and depressive-like behaviors in tumor-bearing mice. We observed

17 increased IL-1 $\beta$ mRNA in the brain, reduced VWRA and depressive-like behavior in tumor-

18 bearing mice with no decrease in home-cage locomotor activity. Furthermore, orally

19 administered minocycline prevented tumor-induced increases in IL-1 $\beta$ and IL-6 mRNA

20 expression in the cortex and hippocampus, decreased depressive-like behavior in the FST at two

21 weeks and increased normalized grip strength at three weeks of tumor growth. The ability of

22 minocycline to increase relative grip strength without increasing muscle mass indicates that there

23 is a motivation component to grip strength testing. Minocycline treatment had no effect on 
1 plasma IL-6, muscle mass or tumor mass, suggesting that the behavioral effects of minocycline

2 were related to decreases in neuroinflammation rather than delayed tumor growth or increased

3 skeletal muscle mass. These results support our overall hypothesis that cytokine-dependent

4 effects of tumor growth on neuroinflammation play a major role in the co-morbidity of fatigue

5 and depression in cancer patients (Bower et al., 2011; Kim et al., 2012; Kirkova et al., 2011;

6 Minton et al., 2012; Phillips and McAuley, 2013). In addition, others have shown that psycho-

7 cognitive therapy is as effective as exercise therapy in reducing fatigue in cancer patients

8 (Gielissen et al., 2006) which further supports an important role for the affective domain in CRF.

9 Further study is needed to determine the potential of minocycline to reduce depression and

10 attenuate fatigue in cancer patients.

\section{5. Acknowledgements}

13 This work was supported by NIH grant R01-NR-012618 to DOM, LEW, and PJR and by NIA 14 grant R01-AG-033028 to JPG.

\section{Financial disclosure}

17 The authors of this manuscript declare that there are no actual or potential conflicts of interest.

\section{References}

Acharyya, S., Ladner, K.J., Nelsen, L.L., Damrauer, J., Reiser, P.J., Swoap, S., and Guttridge, D.C. (2004). Cancer cachexia is regulated by selective targeting of skeletal muscle gene

22 products. The Journal of clinical investigation 114, 370-378.

23 Baracos, V.E., Reiman, T., Mourtzakis, M., Gioulbasanis, I., and Antoun, S. (2010). Body with the use of computed tomography image analysis. The American journal of clinical nutrition

26 91, 1133S-1137S. 
1 Berger, A.M., Gerber, L.H., and Mayer, D.K. (2012). Cancer-related fatigue: implications for 2 breast cancer survivors. Cancer 118, 2261-2269.

3 Bicer, S., Reiser, P.J., Ching, S., and Quan, N. (2009). Induction of muscle weakness by local 4 inflammation: an experimental animal model. Inflammation research 58, 175-183. Bower, J.E. (2007). Cancer-related fatigue: links with inflammation in cancer patients and survivors. Brain, behavior, and immunity 21, 863-871.

Bower, J.E., Ganz, P.A., Irwin, M.R., Kwan, L., Breen, E.C., and Cole, S.W. (2011). Inflammation and behavioral symptoms after breast cancer treatment: do fatigue, depression, and sleep disturbance share a common underlying mechanism? Journal of clinical oncology 29 , 3517-3522.

Bower, J.E., and Lamkin, D.M. (2013). Inflammation and cancer-related fatigue: mechanisms, contributing factors, and treatment implications. Brain, behavior, and immunity $30 \mathrm{Suppl}$, S4857.

Braun, T.P., Zhu, X., Szumowski, M., Scott, G.D., Grossberg, A.J., Levasseur, P.R., Graham, K., Khan, S., Damaraju, S., Colmers, W.F., et al. (2011). Central nervous system inflammation induces muscle atrophy via activation of the hypothalamic-pituitary-adrenal axis. The Journal of 17 experimental medicine 208, 2449-2463.

18 Cao, D.X., Wu, G.H., Zhang, B., Quan, Y.J., Wei, J., Jin, H., Jiang, Y., and Yang, Z.A. (2010). Resting energy expenditure and body composition in patients with newly detected cancer. Clin Nutr 29, 72-77.

Carmichael, M.D., Davis, J.M., Murphy, E.A., Brown, A.S., Carson, J.A., Mayer, E.P., and Ghaffar, A. (2006). Role of brain IL-1beta on fatigue after exercise-induced muscle damage. American journal of physiology. Regulatory, integrative and comparative physiology 291,

24 R1344-1348.

Cosper, P.F., and Leinwand, L.A. (2011). Cancer causes cardiac atrophy and autophagy in a sexually dimorphic manner. Cancer research 71, 1710-1720.

Diffee, G.M., Kalfas, K., Al-Majid, S., and McCarthy, D.O. (2002). Altered expression of skeletal muscle myosin isoforms in cancer cachexia. American journal of physiology. Cell physiology 283, C1376-1382.

Donnelly, D.J., Gensel, J.C., Ankeny, D.P., van Rooijen, N., and Popovich, P.G. (2009). An efficient and reproducible method for quantifying macrophages in different experimental models of central nervous system pathology. J Neurosci Methods 181, 36-44.

33 Fearon, K.C., Glass, D.J., and Guttridge, D.C. (2012). Cancer cachexia: mediators, signaling, and 34 metabolic pathways. Cell metabolism 16, 153-166.

35 Gielissen, M.F., Verhagen, S., Witjes, F., and Bleijenberg, G. (2006). Effects of cognitive behavior therapy in severely fatigued disease-free cancer patients compared with patients waiting for cognitive behavior therapy: a randomized controlled trial. Journal of clinical oncology:

38 official journal of the American Society of Clinical Oncology 24, 4882-4887.

39 Godbout, J.P., Moreau, M., Lestage, J., Chen, J., Sparkman, N.L., J, O.C., Castanon, N., Kelley,

40 K.W., Dantzer, R., and Johnson, R.W. (2008). Aging exacerbates depressive-like behavior in 
mice in response to activation of the peripheral innate immune system.

2 Neuropsychopharmacology 33, 2341-2351.

3 Graves, E., Ramsay, E., and McCarthy, D.O. (2006). Inhibitors of COX activity preserve muscle mass in mice bearing the Lewis lung carcinoma, but not the B16 melanoma. Research in nursing \& health 29, 87-97.

Haroon, E., Raison, C.L., and Miller, A.H. (2012). Psychoneuroimmunology meets neuropsychopharmacology: translational implications of the impact of inflammation on behavior. Neuropsychopharmacology 37, 137-162.

Henry, C.J., Huang, Y., Wynne, A., Hanke, M., Himler, J., Bailey, M.T., Sheridan, J.F., and Godbout, J.P. (2008). Minocycline attenuates lipopolysaccharide (LPS)-induced neuroinflammation, sickness behavior, and anhedonia. Journal of neuroinflammation 5, 15.

12 Hofman, M., Ryan, J.L., Figueroa-Moseley, C.D., Jean-Pierre, P., and Morrow, G.R. (2007).

13 Cancer-related fatigue: the scale of the problem. The oncologist 12 Suppl 1, 4-10.

14 Hopwood, N., Maswanganyi, T., and Harden, L.M. (2009). Comparison of anorexia, lethargy, 15 and fever induced by bacterial and viral mimetics in rats. Canadian journal of physiology and 16 pharmacology 87, 211-220.

17 Husson, O., Nieuwlaat, W.A., Oranje, W.A., Haak, H.R., van de Poll-Franse, L.V., and Mols, F. 18 (2013). Fatigue Among Short- and Long-Term Thyroid Cancer Survivors: Results from the 19 Population-Based PROFILES Registry. Thyroid : official journal of the American Thyroid 20 Association 23, 1247-1255. Johns, N., Hatakeyama, S., Stephens, N.A., Degen, M., Degen, S., Frieauff, W., Lambert, C., Ross, J.A., Roubenoff, R., Glass, D.J., et al. (2014). Clinical classification of cancer cachexia: phenotypic correlates in human skeletal muscle. PloS one 9, e83618. Kim, H.J., Barsevick, A.M., Fang, C.Y., and Miaskowski, C. (2012). Common biological pathways underlying the psychoneurological symptom cluster in cancer patients. Cancer nursing 35, E1-E20.

Kirkova, J., Aktas, A., Walsh, D., and Davis, M.P. (2011). Cancer symptom clusters: clinical and research methodology. Journal of palliative medicine 14, 1149-1166. Lamkin, D.M., Lutgendorf, S.K., Lubaroff, D., Sood, A.K., Beltz, T.G., and Johnson, A.K. (2011). Cancer induces inflammation and depressive-like behavior in the mouse: modulation by social housing. Brain, behavior, and immunity 25, 555-564.

Minton, O., Alexander, S., and Stone, P.C. (2012). Identification of factors associated with cancer related fatigue syndrome in disease-free breast cancer patients after completing primary treatment. Breast cancer research and treatment 136, 513-520.

Mols, F., Husson, O., Roukema, J.A., and van de Poll-Franse, L.V. (2013). Depressive symptoms are a risk factor for all-cause mortality: results from a prospective population-based study among 3,080 cancer survivors from the PROFILES registry. Journal of cancer survivorship : research and practice 7, 484-492. and metabolic impairments in the characterization of the C-26 murine model of cancer cachexia. Disease models \& mechanisms 5, 533-545. 
Murphy, K.T., Chee, A., Trieu, J., Naim, T., and Lynch, G.S. (2013). Inhibition of the reninangiotensin system improves physiological outcomes in mice with mild or severe cancer cachexia. International journal of cancer. 133, 1234-1246.

Nikodemova, M., Duncan, I.D., and Watters, J.J. (2006). Minocycline exerts inhibitory effects on multiple mitogen-activated protein kinases and IkappaBalpha degradation in a stimulusspecific manner in microglia. Journal of neurochemistry 96, 314-323.

Novak, C.M., Burghardt, P.R., and Levine, J.A. (2012). The use of a running wheel to measure activity in rodents: relationship to energy balance, general activity, and reward. Neuroscience and biobehavioral reviews 36, 1001-1014.

Okayama, T., Kokura, S., Ishikawa, T., Adachi, S., Hattori, T., Takagi, T., Handa, O., Naito, Y., and Yoshikawa, T. (2009). Antitumor effect of pretreatment for colon cancer cells with hyperthermia plus geranylgeranylacetone in experimental metastasis models and a subcutaneous tumor model of colon cancer in mice. International journal of hyperthermia : the official journal of European Society for Hyperthermic Oncology, North American Hyperthermia Group 25, 141149.

Pertl, M.M., Hevey, D., Boyle, N.T., Hughes, M.M., Collier, S., O'Dwyer, A.M., Harkin, A., Kennedy, M.J., and Connor, T.J. (2013). C-reactive protein predicts fatigue independently of depression in breast cancer patients prior to chemotherapy. Brain, behavior, and immunity 34 , 108-119.

Phillips, S.M., and McAuley, E. (2013). Physical activity and fatigue in breast cancer survivors: a panel model examining the role of self-efficacy and depression. Cancer epidemiology, biomarkers \& prevention : a publication of the American Association for Cancer Research, cosponsored by the American Society of Preventive Oncology 22, 773-781.

Pyter, L.M., Pineros, V., Galang, J.A., McClintock, M.K., and Prendergast, B.J. (2009). Peripheral tumors induce depressive-like behaviors and cytokine production and alter hypothalamic-pituitary-adrenal axis regulation. Proceedings of the National Academy of Sciences of the United States of America 106, 9069-9074.

28 Roberts, B.M., Frye, G.S., Ahn, B., Ferreira, L.F., and Judge, A.R. (2013). Cancer cachexia decreases specific force and accelerates fatigue in limb muscle. Biochemical and biophysical

30 research communications $435,488-492$.

31 Saligan, L.N., and Kim, H.S. (2012). A systematic review of the association between 32 immunogenomic markers and cancer-related fatigue. Brain, behavior, and immunity $26,830-$ 33848.

34 Sandri, M. (2013). Protein breakdown in muscle wasting: role of autophagy-lysosome and 35 ubiquitin-proteasome. The international journal of biochemistry \& cell biology 45, 2121-2129.

36 Schmitt, T.L., Martignoni, M.E., Bachmann, J., Fechtner, K., Friess, H., Kinscherf, R., and 37 Hildebrandt, W. (2007). Activity of the Akt-dependent anabolic and catabolic pathways in 38 muscle and liver samples in cancer-related cachexia. J Mol Med (Berl) 85, 647-654.

39 Taskin, S., Stumpf, V.I., Bachmann, J., Weber, C., Martignoni, M.E., and Friedrich, O. (2014).

40 Motor protein function in skeletal abdominal muscle of cachectic cancer patients. Journal of

41 cellular and molecular medicine 18, 69-79. 
1 Toledo, M., Busquets, S., Sirisi, S., Serpe, R., Orpi, M., Coutinho, J., Martinez, R., Lopez-

2 Soriano, F.J., and Argiles, J.M. (2011). Cancer cachexia: physical activity and muscle force in 3 tumour-bearing rats. Oncology reports 25, 189-193.

4 Toth, M.J., Miller, M.S., Callahan, D.M., Sweeny, A.P., Nunez, I., Grunberg, S.M., Der-

5 Torossian, H., Couch, M.E., and Dittus, K. (2013). Molecular mechanisms underlying skeletal

6 muscle weakness in human cancer: reduced myosin-actin cross-bridge formation and kinetics. J

7 Appl Physiol (1985) 114, 858-868.

8 Vissers, P.A., Thong, M.S., Pouwer, F., Zanders, M.M., Coebergh, J.W., and van de Poll-Franse,

9 L.V. (2013). The impact of comorbidity on Health-Related Quality of Life among cancer

10 survivors: analyses of data from the PROFILES registry. Journal of cancer survivorship :

11 research and practice.

12 Wang, X.S., Williams, L.A., Krishnan, S., Liao, Z., Liu, P., Mao, L., Shi, Q., Mobley, G.M.,

13 Woodruff, J.F., and Cleeland, C.S. (2012). Serum sTNF-R1, IL-6, and the development of

14 fatigue in patients with gastrointestinal cancer undergoing chemoradiation therapy. Brain,

15 behavior, and immunity 26, 699-705.

16 Weber, M.A., Krakowski-Roosen, H., Schroder, L., Kinscherf, R., Krix, M., Kopp-Schneider,

17 A., Essig, M., Bachert, P., Kauczor, H.U., and Hildebrandt, W. (2009). Morphology,

18 metabolism, microcirculation, and strength of skeletal muscles in cancer-related cachexia. Acta

19 Oncol 48, 116-124.

20 Wohleb, E.S., Hanke, M.L., Corona, A.W., Powell, N.D., Stiner, L.M., Bailey, M.T., Nelson,

21 R.J., Godbout, J.P., and Sheridan, J.F. (2011). beta-Adrenergic receptor antagonism prevents

22 anxiety-like behavior and microglial reactivity induced by repeated social defeat. The Journal of

23 neuroscience 31, 6277-6288.

24 Wood, L.J., Nail, L.M., Gilster, A., Winters, K.A., and Elsea, C.R. (2006). Cancer

25 chemotherapy-related symptoms: evidence to suggest a role for proinflammatory cytokines.

26 Oncology nursing forum 33, 535-542.

27 Wood, L.J., and Weymann, K. (2013). Inflammation and neural signaling: etiologic mechanisms

28 of the cancer treatment-related symptom cluster. Current opinion in supportive and palliative

29 care 7, 54-59.

$30 \mathrm{Xu}, \mathrm{H}$. , Crawford, D., Hutchinson, K.R., Youtz, D.J., Lucchesi, P.A., Velten, M., McCarthy,

31 D.O., and Wold, L.E. (2011). Myocardial dysfunction in an animal model of cancer cachexia.

32 Life sciences 88, 406-410.

33 Yang, M., Kim, J., Kim, J.-S., Kim, S.-H., Kim, J.-C., Kang, M.-J., Jung, U., Shin, T., Wang, H.,

34 and Moon, C. (2014). Hippocampal dysfunctions in tumor-bearing mice. Brain, behavior, and

35 immunity $36,147-155$.

36 Zombeck, J.A., Fey, E.G., Lyng, G.D., and Sonis, S.T. (2013). A clinically translatable mouse

37 model for chemotherapy-related fatigue. Comparative medicine 63, 491-497. 


\section{Figure Legends}

Figure 1. Tumor growth was associated with muscle mass loss and muscle weakness. Mice were inoculated s.c. with PBS (Control) or PBS with C26 adenocarcinoma cells (Tumor). A) Tumor mass, B) body mass, and C) gastrocnemius muscle mass was determined 1, 2, and 3 weeks after inoculation ( $n=6)$. D) Grip strength (Newtons) was determined at baseline (day 0) and then again at 2 and 3 weeks $(n=8)$. E) The normalized grip strength (Newtons of grip strength to kilograms of body mass) was also determined at the 3 week endpoint $(n=8)$. Data are expressed as mean \pm SEM. Means with * are different from control mice $(p<0.05)$.

Figure 2. Tumor growth increased fatigue- and depressive-like behavior. A) Voluntary wheel running activity (VWRA) was determined overnight at baseline and again at 1, 2, and 3 weeks after tumor cell inoculation. B) Sucrose preference was determined 1, 2, and 3 weeks after tumor cell inoculation. C) Home cage activity was determined 2 weeks after tumor inoculation. Control and tumor mice were exposed to the forced swim test (FST) at 2 weeks and D) latency to become immobile and E) total time immobile were determined $(n=6)$. Bars represent the mean \pm SEM. Means with * are different from control $(p<0.05)$.

Figure 3. Increased IL-1 $\beta$ and IL-6 mRNA expression in the brain of tumor-bearing mice. IL-1 $\beta$ mRNA expression was determined in the A) hippocampus (HPC) and B) cortex (CX) 2 and 3 weeks after tumor cell injection. IL-6 mRNA was also determined in the C) HPC and D) CX (n=6). E) Representative images of Iba-1 labeling of microglia in the HPC and CX collected 3 weeks after tumor cell inoculation. Inset includes enlarged image of Iba- $1^{+}$cell indicated by white arrow. Proportional area for Iba-1 labeling in the F) HPC and G) CX (n=6). Data are 
1 expressed as mean \pm SEM. Means with * are different from control mice $(p<0.05)$ and means

2 with $\ddagger$ are different from Tumor-Week $2(p<0.05)$.

4 Figure 4. Minocycline attenuated depressive-like behavior and restored grip strength in

5 tumor-bearing mice. Control and Tumor-bearing mice were administered vehicle or

6 minocycline (Mino) in the drinking water starting one day after tumor cell injection. A) Control

7 and Tumor mice were exposed to the forced swim test at 2 weeks and total time immobile was

8 determined. B) Grip strength was assessed and normalized to body mass at the 3 week endpoint.

9 C) Tumor mass, D) muscle mass, and E) plasma IL-6 levels were determined at 3 weeks. Means

10 with $*$ are different from control mice $(p<0.05)$, means with $\neq$ are different from Tumor-Vehicle

11 mice $(p<0.05)(\mathrm{n}=8-12)$.

13 Figure 5. Minocycline attenuated neuroinflammation in tumor-bearing mice. Control and

14 Tumor-bearing mice were administered vehicle or minocycline (Mino) in the drinking water. A-

15 D) IL-1 $\beta$ and IL-6 mRNA expression was determined in the HPC and CX at 3 weeks. Data are

16 expressed as mean \pm SEM. Means with * are different from control mice $(p<0.05)$, means with +

17 tend to be different from control mice $(p=0.07)(n=8-12)$. 
3 Table 1: Soleus in vitro contractile properties.

\begin{tabular}{lcccc}
\hline Parameters & Control & Tumor & Tumor & Tumor \\
& & Week 1 & Week 2 & Week 3 \\
\hline Twitch & $52 \pm 4$ & $90 \pm 7^{*}$ & $81 \pm 5^{*}$ & $79 \pm 1^{*}$ \\
Time to peak (ms) & $82 \pm 10$ & $259 \pm 41^{*}$ & $206 \pm 28^{*}$ & $167 \pm 33^{*}$ \\
Time to relax 50\% $(\mathrm{ms})$ & $52 \pm 3$ & $51 \pm 3$ & $46 \pm 3$ & $45 \pm 4$ \\
Absolute force $(\mathrm{mN})$ & $86 \pm 5$ & $95 \pm 4$ & $95 \pm 6$ & $94 \pm 7$ \\
Specific force $\left(\mathrm{kN} / \mathrm{m}^{2}\right)$ & & & & \\
\end{tabular}

\section{Tetanus}

Time to relax $50 \%$ (ms)

$$
151 \pm 5
$$

$178 \pm 11$

$161 \pm 8$

$198 \pm 20$

Absolute force $(\mathrm{mN})$

$$
206 \pm 14
$$

$180 \pm 6$

$158 \pm 11^{*}$

$153 \pm 9 *$

Specific force $\left(\mathrm{kN} / \mathrm{m}^{2}\right)$

$339 \pm 20$

$336 \pm 13$

$324 \pm 22$

$316 \pm 19$

Fatigue (2 min /initial

$0.53 \pm 0.03$

$0.42 \pm 0.03$

$0.47 \pm 0.02$

$0.50 \pm 0.06$ force)

\footnotetext{
Number of mice

6

6

6

6

4

Mice were inoculated s.c. with PBS (Control) or PBS with C26 adenocarcinoma cells (Tumor).

6 Control and tumor mice were sacrificed at 1,2 or 3 weeks after tumor cell inoculation and

7 contractile properties of soleus skeletal muscle were determined in vitro $(n=6)$. Values are mean

$8 \pm$ sem. Means with * are different from control mice $(p<0.05)$
} 
3 Table 2: EDL in vitro contractile properties.

\begin{tabular}{|c|c|c|c|c|}
\hline Parameters & Control & $\begin{array}{c}\text { Tumor } \\
\text { Week } 1\end{array}$ & $\begin{array}{l}\text { Tumor } \\
\text { Week } 2\end{array}$ & $\begin{array}{l}\text { Tumor } \\
\text { Week } 3\end{array}$ \\
\hline \multicolumn{5}{|l|}{ Twitch } \\
\hline Time to peak (ms) & $26 \pm 1$ & $21 \pm 1 *$ & $21 \pm 1 *$ & $29 \pm 2$ \\
\hline Time to relax $50 \%(\mathrm{~ms})$ & $41 \pm 4$ & $31 \pm 2$ & $23 \pm 1 *$ & $45 \pm 5$ \\
\hline Absolute force $(\mathrm{mN})$ & $124 \pm 5$ & $93 \pm 3^{*}$ & $98 \pm 7 *$ & $91 \pm 11 *$ \\
\hline Specific force $\left(\mathrm{kN} / \mathrm{m}^{2}\right)$ & $139 \pm 5$ & $125 \pm 6$ & $129 \pm 8$ & $137 \pm 13$ \\
\hline \multicolumn{5}{|l|}{ Tetanus } \\
\hline Time to relax $50 \%(\mathrm{~ms})$ & $58 \pm 3$ & & $52 \pm 1$ & $64 \pm 4$ \\
\hline Absolute force $(\mathrm{mN})$ & $326 \pm 14$ & $251 \pm 9^{*}$ & $288 \pm 21$ & $249 \pm 29^{*}$ \\
\hline Specific force $\left(\mathrm{kN} / \mathrm{m}^{2}\right)$ & \pm 17 & $336 \pm 16$ & $380 \pm 23$ & $373 \pm 36$ \\
\hline Fatigue ( $2 \mathrm{~min} /$ initial for & $0.09 \pm 0.0$ & $0.09 \pm 0.01$ & $0.08 \pm 0.01$ & $0.10 \pm 0.01$ \\
\hline
\end{tabular}

Number of mice

6

6

6

6

4

Mice were inoculated s.c. with PBS (Control) or PBS with C26 adenocarcinoma cells (Tumor).

Control and tumor mice were sacrificed at 1,2 or 3 weeks after tumor cell inoculation and contractile properties of Extensor digitorum longus (EDL) skeletal muscle were determined in vitro $(n=6)$. Values are mean \pm sem. Means with $*$ are different from control mice $(p<0.05)$. 
3 Table 3: Tibialis in situ contractile properties.

\begin{tabular}{lll}
\hline Parameters & Control & Tumor
\end{tabular}

\section{Twitch}

Time to peak (ms)

Time to relax $50 \%(\mathrm{~ms})$

Time to relax $90 \%(\mathrm{~ms})$

Absolute force $(\mathrm{mN})$

Specific force $\left(\mathrm{kN} / \mathrm{m}^{2}\right)$

\section{Tetanus}

Time to relax 50\% (ms)

Time to relax $90 \%$ (ms)

Absolute force $(\mathrm{mN})$

Specific force $\left(\mathrm{kN} / \mathrm{m}^{2}\right)$

Fatigue (2 min force/initial force)
$56 \pm 4$

$96 \pm 9$

$1127 \pm 65$

$323 \pm 17$

$0.22 \pm 0.04$
$27 \pm 1$

$27 \pm 2$

$57 \pm 4$

$353 \pm 16^{*}$

$141 \pm 4$

\section{Number of mice}

6

$$
50 \pm 4
$$$$
88 \pm 8
$$

$859 \pm 48^{*}$

5 Mice were inoculated s.c. with PBS (Control) or PBS with C26 adenocarcinoma cells (Tumor).

In situ contraction analyses of the tibialis were determined 3 weeks after tumor cell inoculation

$7 \quad(n=6)$. Values are mean \pm sem. Means with $*$ are different from control mice $(p<0.05)$. 
FIGURE 1

A.

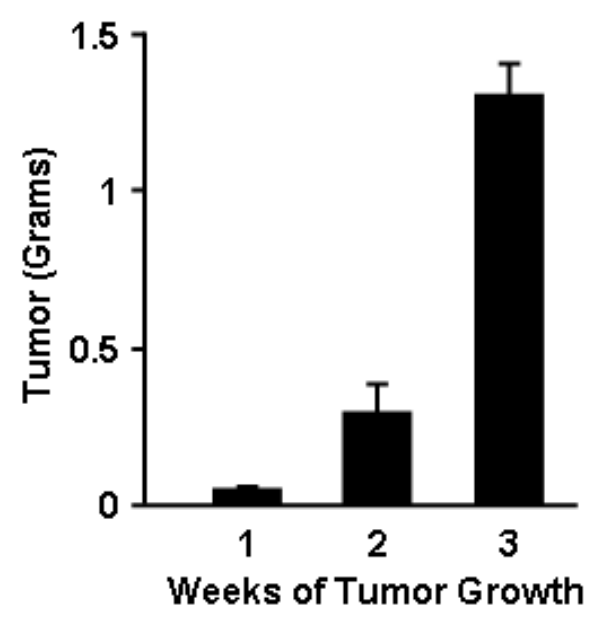

B.

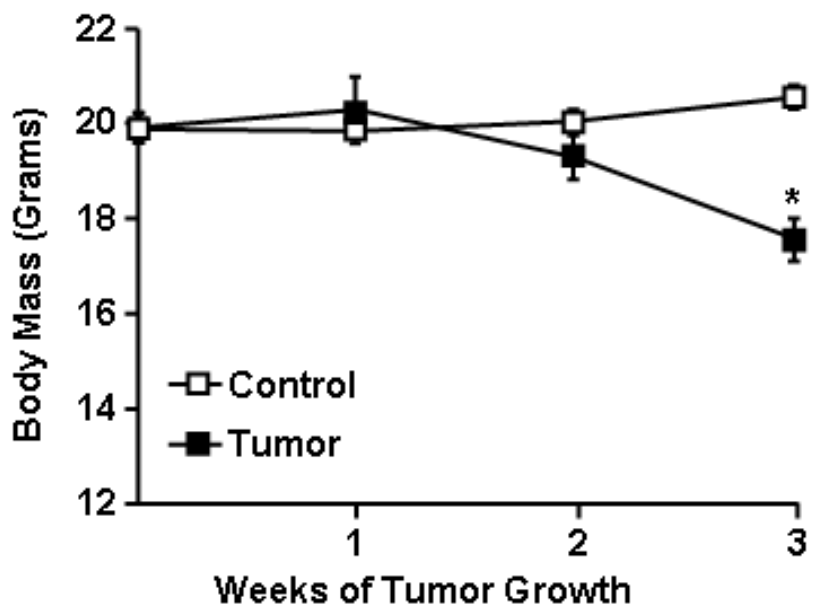

C.

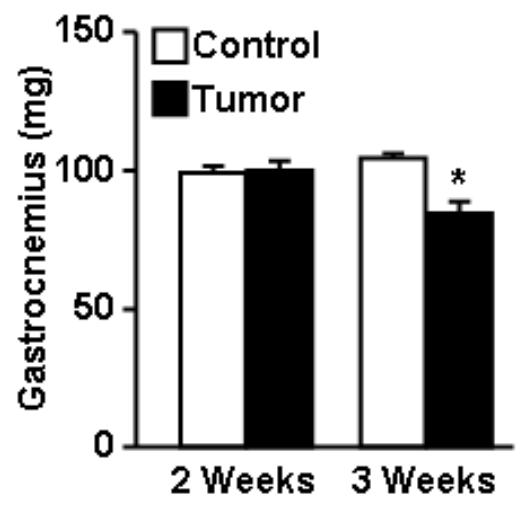

D.

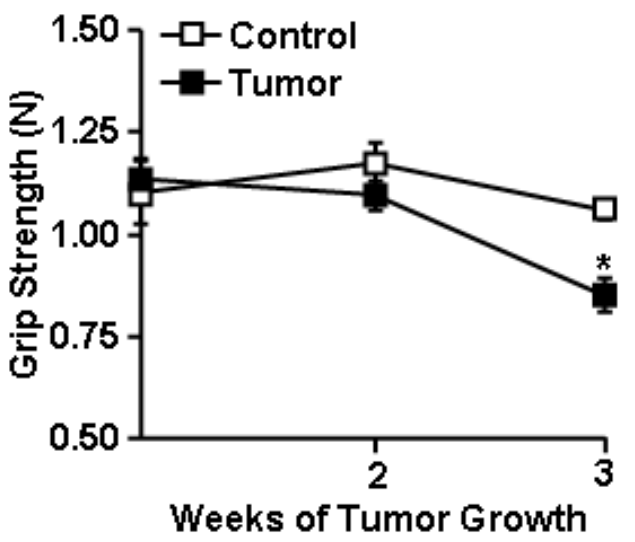

E. ${ }_{60}^{\square \text { Control }}$

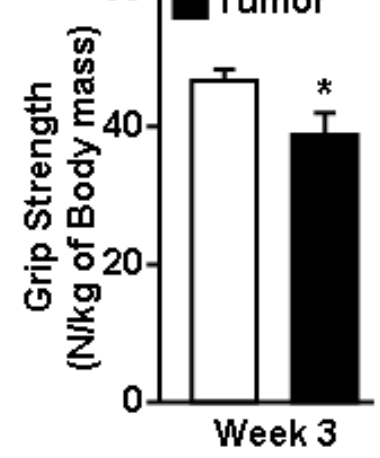


FIGURE 2

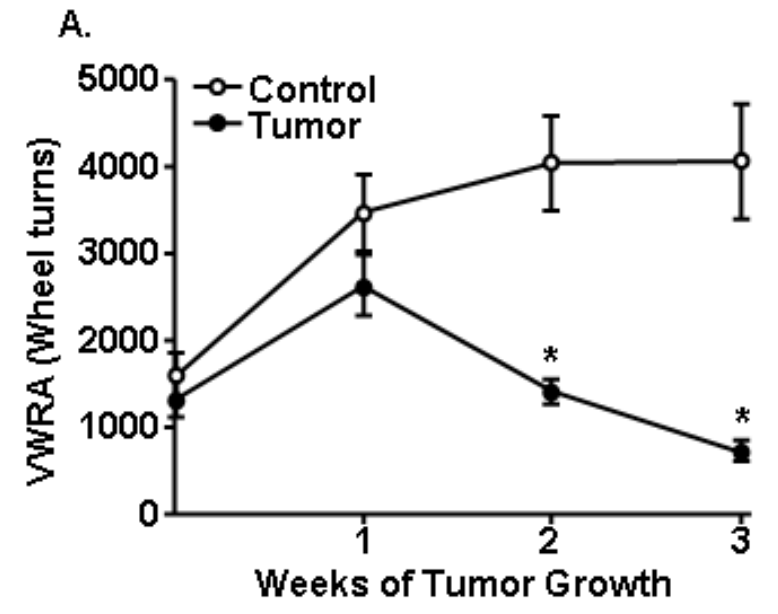

B.
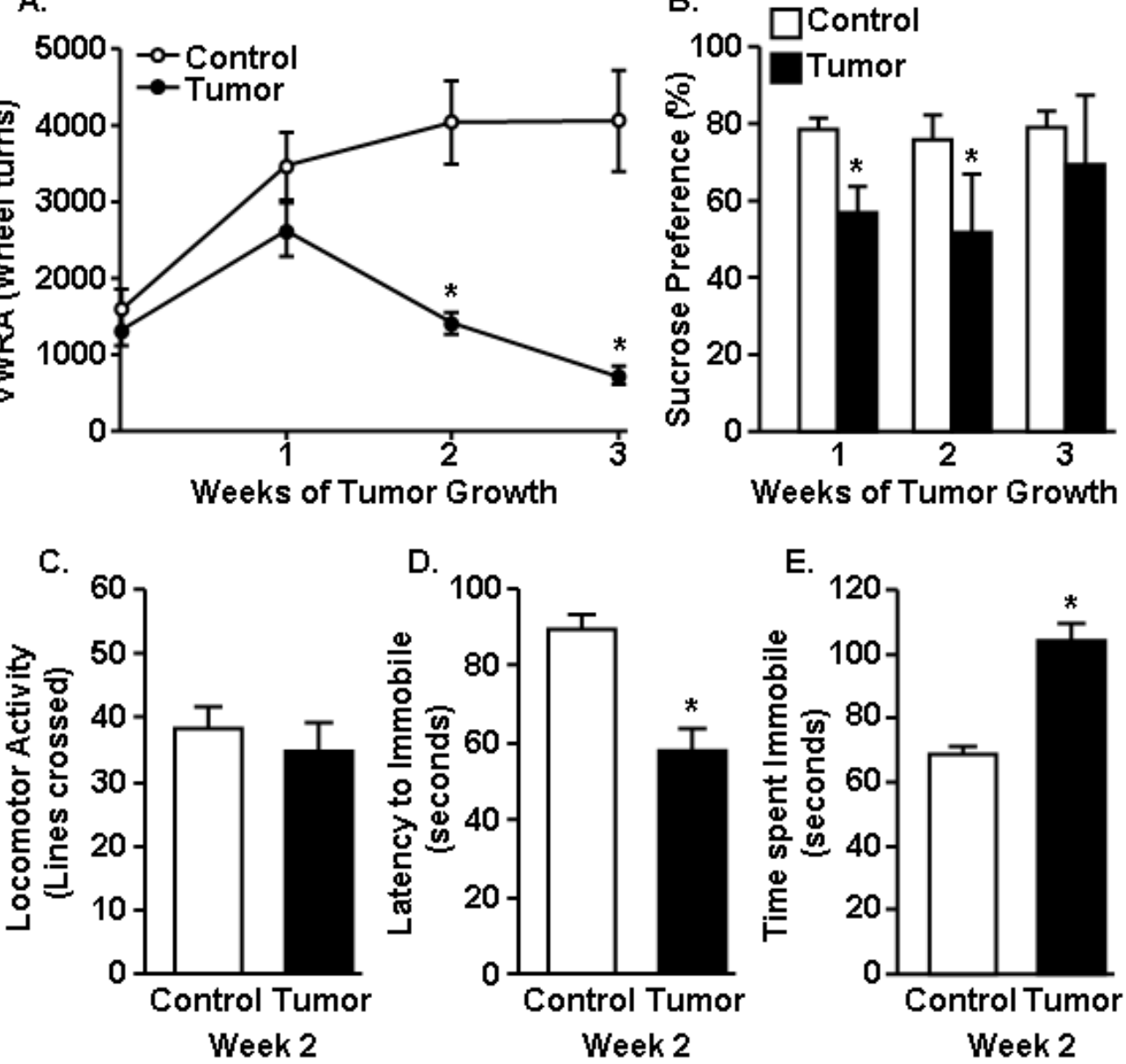

D.

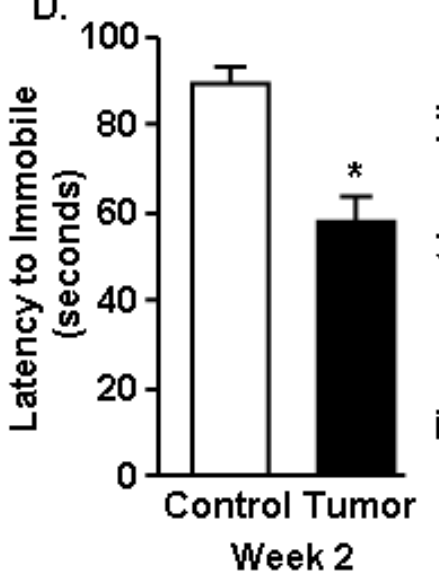

E.

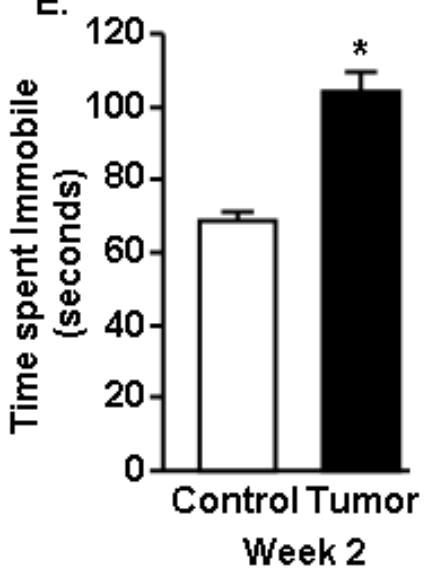


FIGURE 3
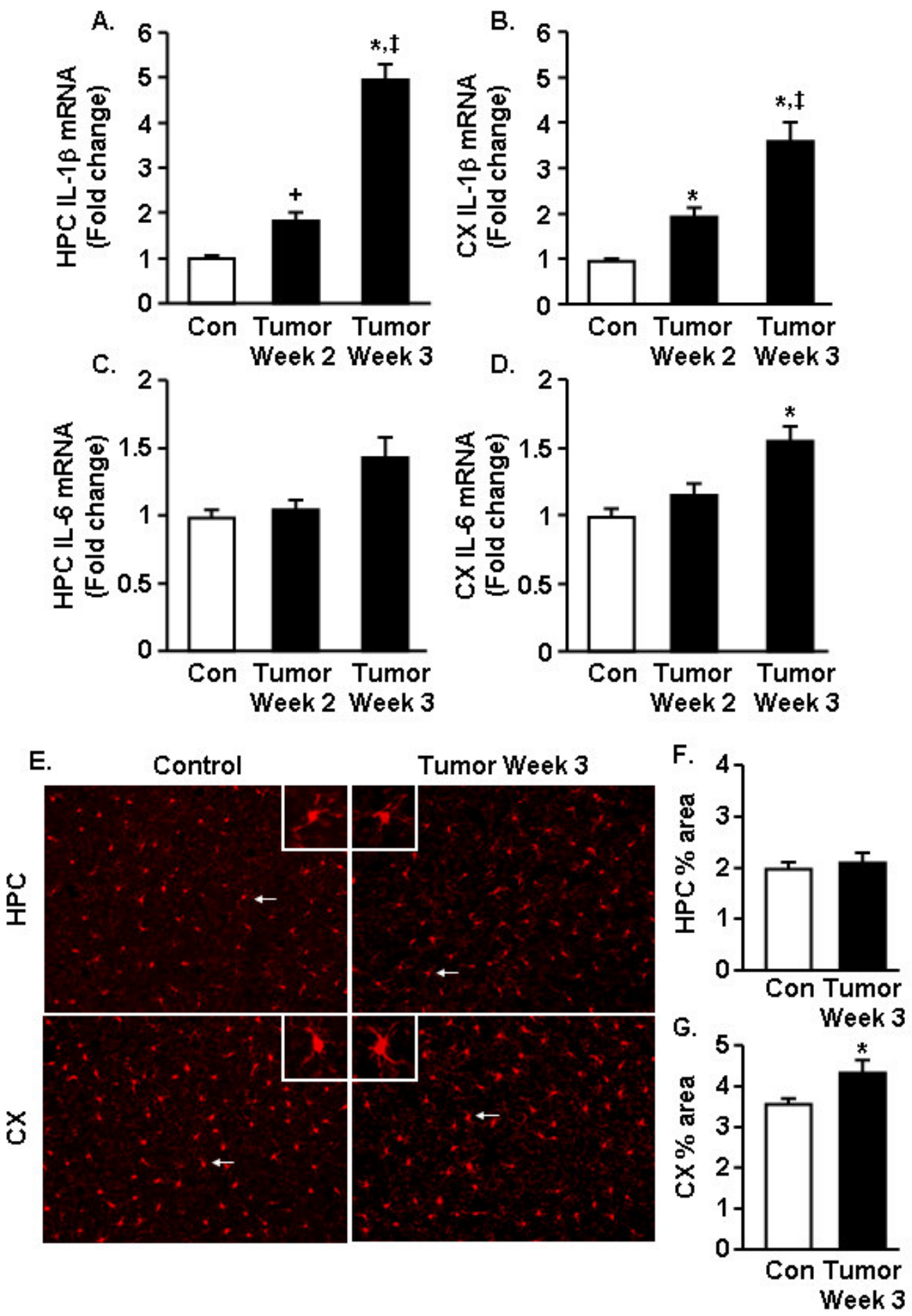
FIGURE 4
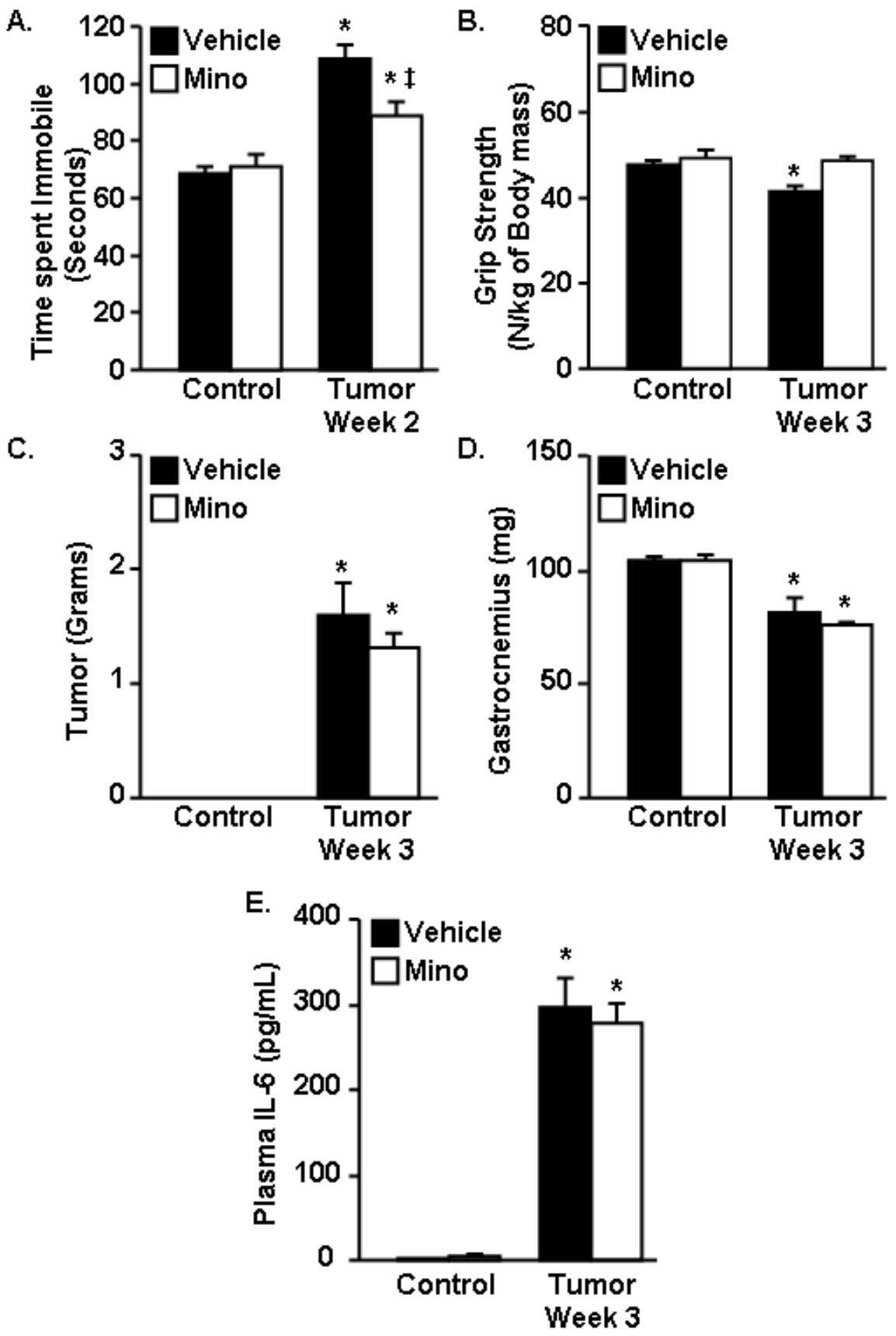
FIGURE 5
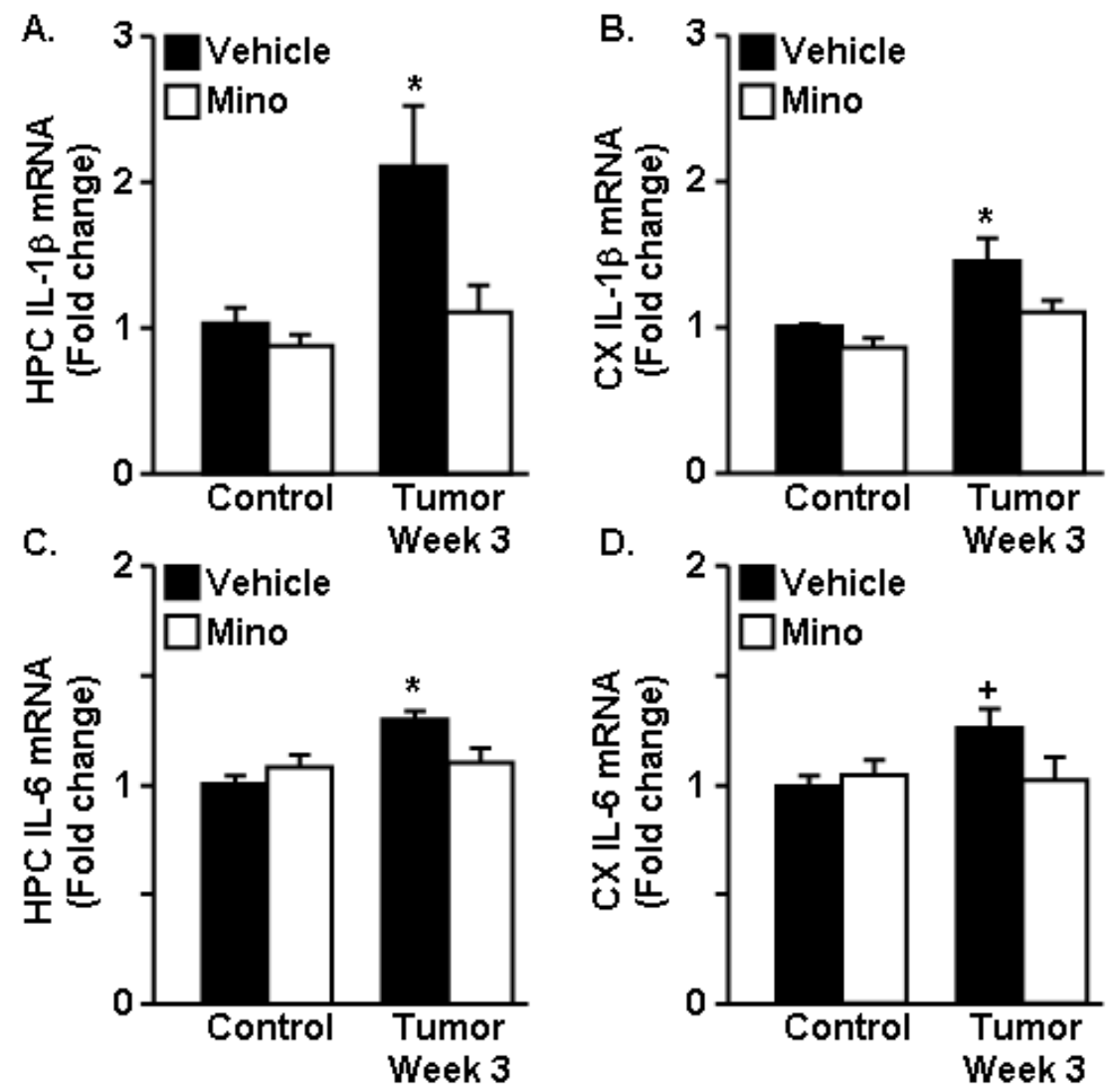